Simón Gaviria Muñoz*

Luis Fernando Mejía Alzate**

Gabriel Piraquive Galeano***

Gabriel Cifuentes Ghidini****

Redy López López *****

Yesid Parra Vera*****

\title{
EL DIVIDENDO ECONÓMICO DE LA PAZ EN COLOMBIA: LECCIONES DE LA EXPERIENCIA INTERNACIONAL
}

Este documento presenta un análisis detallado del dividendo económico de la paz en 36 países que han terminado sus conflictos armados. A diferencia de estudios previos basados en estimaciones contrafactuales, en este trabajo se utiliza la evidencia empírica disponible sobre otros países que han atravesado procesos que se asemejan al del caso colombiano.

Los resultados obtenidos permiten afirmar que el dividendo económico de la paz se refleja en un crecimiento medio anual del PIB superior de entre 1,1 y 1,9 puntos porcentuales comparando antes y después del conflicto, así como en un incremento de 54 por 100 en el PIB per cápita en diez años sin incluir el componente tendencial.

Palabras clave: crecimiento del PIB, desempleo, economías postconflicto, inversión productiva.

JEL: D74, E52, J64.

*Director General del Departamento Nacional de Planeación, Colombia.

** Subdirector General Sectorial del Departamento Nacional de Planeación, Colombia.

*** Director de Estudios Económicos del Departamento Nacional de Planeación, Colombia.

**** Director de Justicia, Seguridad y Gobierno del Departamento Nacional de Planeación, Colombia.

${ }^{\star \star \star \star \star}$ Asesores de la Subdirección General Sectorial del Departamento Nacional de Planeación, Colombia.

Este trabajo contó con la excelente colaboración de María Alejandra Arias Hernández, Nancy Daza Baez, Diego Maldonado Castellanos, Manuel Fernando Moscoso Rojas, Daniela Pérez Giraldo y Sebastián Riomalo Clavijo, a quienes los autores se lo agradecen especialmente.

Versión de marzo de 2017.

\section{Introducción}

Colombia se enfrenta hoy a una coyuntura histórica por cuenta de la implementación del proceso de paz que el Gobierno nacional adelanta con la guerrilla de las FARC-EP. Este proceso plantea la importancia de contar con cifras sobre el eventual impacto macroeconómico de terminar con este conflicto. Existe una amplia literatura sobre los costos económicos del $D$ 
conflicto armado y los eventuales beneficios de un acuerdo de paz, remitiendo buena parte de los cálculos a ejercicios contrafactuales. En este trabajo se calculan los potenciales beneficios económicos de la paz con base en la experiencia observada en países que atravesaron por procesos similares; es decir, remitiéndose a cifras observadas.

En particular, el estudio que aquí se presenta analiza el efecto de la terminación del conflicto en 36 países, 18 de los cuales tienen características similares a las del caso colombiano. El análisis para estos países involucra variables como el crecimiento de la economía, la demanda interna y externa, la estructura de crecimiento de la oferta, la inserción de las economías en el contexto internacional, el desempleo y la inflación, el recaudo y el gasto fiscal, así como los flujos de inversión extranjera directa.

Es importante enfatizar que la metodología usada en este documento compara los promedios de las variables antes y después de los acuerdos, lo que permite controlar de manera sencilla ciertos efectos fijos que pudieran estar afectando los resultados. De igual forma, la gran diversidad de fechas en las que ocurrieron los acuerdos permite dar cierta tranquilidad sobre algunos efectos temporales que pudieran estar afectando al comportamiento de las distintas variables. Si bien el documento no involucra un análisis econométrico sofisticado, la metodología de eventos utilizada permite dar órdenes de magnitud ilustrativas sobre el potencial impacto económico de la paz.

Los resultados muestran que tras la terminación del conflicto viene una importante mejora en la confianza, lo que se constituye en el principal dividendo de la paz. Lo anterior se manifiesta en aumentos en la inversión productiva, crecimiento en el consumo y mayores flujos de capital externo, vía aumentos en la inversión extranjera. Estos factores permiten elevar la tasa de crecimiento de la economía, el ingreso per cápita y, en general, el bienestar de la población.

En particular, de acuerdo con los resultados del estudio, el dividendo económico de la paz se reflejaría en un crecimiento medio anual del PIB de entre 1,1 y 1,9 puntos porcentuales superior al promedio preconflicto, así como en un incremento del 54 por 100 en el PIB per cápita en diez años sin incluir el componente tendencial. Por el lado de la demanda, comparando los crecimientos medios antes y después del conflicto, la mayor confianza sobre las economías postconflicto genera un aumento de 2,5 pp (puntos porcentuales) en la tasa de crecimiento del consumo de los hogares y conduce a un incremento de 5,5 pp en la inversión como porcentaje del PIB. Asimismo, permite que la inversión extranjera directa se triplique en diez años, e inserta de forma considerable las economías en el comercio internacional, al aumentar en 17,7 pp la tasa de apertura comercial (suma de exportaciones e importaciones como porcentaje del PIB).

Por el lado de la oferta, los resultados muestran un crecimiento de 1,4 pp adicionales en el sector agropecuario, un aumento de 0,8 pp en la tasa de crecimiento de la industria y un destacable aumento de 4,4 pp en el crecimiento del sector de la construcción, que parece beneficiarse de forma especial de las necesidades de infraestructura que surgen una vez finaliza el conflicto armado.

Este trabajo se divide en cuatro partes. La primera es esta introducción. La segunda muestra la revisión de los estudios realizados en Colombia para determinar los beneficios de alcanzar la paz. La tercera explica el desarrollo metodológico para seleccionar de una forma rigurosa las muestras de países. La cuarta $\triangleright$ 
muestra los resultados de la revisión de las variables y los dividendos económicos asociados a cada una de ellas. Finalmente, se presentan algunas implicaciones para la economía colombiana.

\section{Literatura previa sobre el impacto del conflicto en Colombia}

El inventario de estudios sobre el conflicto en Colombia es extenso, y abarca desde el costo económico del conflicto, incluyendo la pérdida de capital humano generada por la violencia, hasta estudios de impacto sectorial y cuantificaciones de los beneficios del cese del conflicto armado. A continuación se hace una breve reseña de esta literatura.

Vargas (2003) hace un cálculo de los costos del conflicto para el país, mostrando cómo el ingreso per cápita habría tenido un crecimiento inferior en 1,25 pp por año, a raíz de la intensificación del conflicto en 1998, con lo cual el PIB total hubiera dejado de crecer dos puntos porcentuales cada año. Querubín (2003) encuentra que una reducción de $10 \mathrm{pp}$ en el crecimiento de diferentes manifestaciones de violencia puede contribuir a un incremento cercano a los 0,6 pp en la tasa de crecimiento del producto per cápita total. González (2006) muestra que los eventos violentos asociados al conflicto armado tienen un efecto negativo sobre el crecimiento económico de algunos departamentos y sobre la convergencia económica regional.

Villa, Restrepo y Moscoso (2013) encuentran que el conflicto le cuesta al país entre 0,5 y $0,8 \mathrm{pp}$ de crecimiento del PIB. Ello significaría que, con conflicto, el PIB de Colombia se duplicaría cada 18,5 años, mientras que sin conflicto tardaría solo 8,5 años. De igual forma, estiman que el ingreso per cápita pasaría de 11.200 dólares (USD) a 16.700 USD en ausencia de conflicto en el 2013, lo que implica una reducción de 8 a 4 años en el tiempo que se requeriría para duplicar el ingreso promedio. Por su parte, Santa María, Rojas y Hernández (2013) encuentran que si las tasas de homicidios y acciones terroristas se reducen en un 50 por 100, el PIB se incrementaría en 2 pp.

A nivel sectorial, hay varios estudios que refuerzan las conclusiones anteriores. En términos del sector agrícola, Ibáñez (2008) encuentra que en ausencia del conflicto armado la producción del sector agropecuario se incrementaría significativamente, lo que permitiría un aumento del consumo de productos agrícolas y del bienestar de la población rural. Pinilla (2013) estima que el conflicto causa una reducción anual en el PIB agropecuario del 3,1 por 100 , cuyo crecimiento promedio desde 2001 ha sido 2,4 por 100. Por su parte, Pinilla y Durán (2013) muestran que se producirían 700.000 toneladas adicionales de alimentos en 110.000 hectáreas adicionales. Finalmente, Kalmanovitz (2014) establece que se recuperarían cerca de 800.000 hectáreas de tierra y Arias e Ibáñez (2014) que 2,1 millones de personas tendrían la posibilidad de regresar a producir en tierras productivas.

A nivel industrial, Rettberg (2008) afirma que en ausencia del conflicto el 75 por 100 de los empresarios aumentarían el empleo y las inversiones destinadas a innovación. Camacho, Rodríguez y Zárate (2014) encuentran que una reducción del 10 por 100 en la intensidad del conflicto reduciría la tasa de salida de empresas manufactureras en un 10,3 por 100. Finalmente, Gaviria (2004) concluye que la emigración del trabajador cualificado se reduciría significativamente. 
A nivel financiero, Marulanda y Paredes (2006) concluyen que con el cese del conflicto habría una extensión de servicios financieros en zonas rurales.

En términos de pérdidas asociadas a la formación de capital humano, Sánchez y Rodríguez (2009) muestran que el conflicto reduce el promedio de los años de educación en 8,8 por 100. Rodríguez y Sánchez (2012) concluyen que en ausencia de conflicto se presentaría una reducción significativa de las tasas de deserción escolar y un aumento de entre 0,6 y 1,2 años en los años de educación. Finalmente, el Instituto Colombiano de Bienestar Familiar -ICBF- (2013) calcula que cerca de 13.000 niños, niñas y adolescentes reclutados entre 1993 y 2013 regresarían a sus hogares.

\section{Dividendo económico de la paz: metodología}

Partiendo de la naturaleza de la situación de conflicto armado en Colombia, el presente trabajo toma información de tres de las fuentes más reconocidas en el análisis de la terminación y resolución de conflictos: la base de datos de conflictos armados de la Universidad de Uppsala, la base de datos Peace Accords Matrix construida por el Kroc Institute de la Universidad de Notre Dame y los Anuarios de Paz de la Escuela de Paz de España. La información de estas fuentes provee un análisis cuantitativo y cualitativo de los conflictos alrededor del mundo, incluyendo información sobre cuántos acuerdos de paz se han firmado e implementado, así como cuáles son los puntos de cada acuerdo que han presentado una mayor complejidad durante la etapa de implementación. A continuación, se detalla cada una de las fuentes de información.

\subsection{Base de datos de conflictos armados de la Universidad de Uppsala, Suecia}

La base de datos de conflictos armados UCDP/PRIO es una de las bases de datos que registra información más antigua referente a conflictos armados en el mundo. Registra conflictos que hayan tenido lugar entre 1946 y 2014, y en los que al menos uno de los actores del conflicto fuera el Gobierno de un Estado. De acuerdo con la revisión realizada, se identificaron 117 conflictos internos que se toman como una primera muestra para el ejercicio comparativo. Esto en tanto que muchos de los conflictos registrados en la base de datos hacen referencia a conflictos interestatales y conflictos que no tienen similitudes con la situación de Colombia, por lo que no fueron tenidos en cuenta en la muestra seleccionada.

\subsection{Peace Accords Matrix del Kroc Institute de la Universidad de Notre Dame, Estados Unidos}

La base de datos del Kroc Institute de la Universidad de Notre Dame, Peace Accords Matrix, es la más amplia de conflictos armados internos. Hace uso de fuentes cualitativas y cuantitativas para hacer seguimiento a 34 acuerdos de paz en 31 países, que se negociaron entre 1989 y 2012. Para cada país se incluye un reporte anual de los resultados de la implementación de los acuerdos durante sus primeros diez años, lo cual permite conocer el avance en su implementación. La base de datos provee un total de 51 variables construidas con base en el contenido de los textos de los acuerdos, e incluye temas como reforma de la justicia, derechos de las mujeres, reforma educativa y manejo de recursos naturales. 


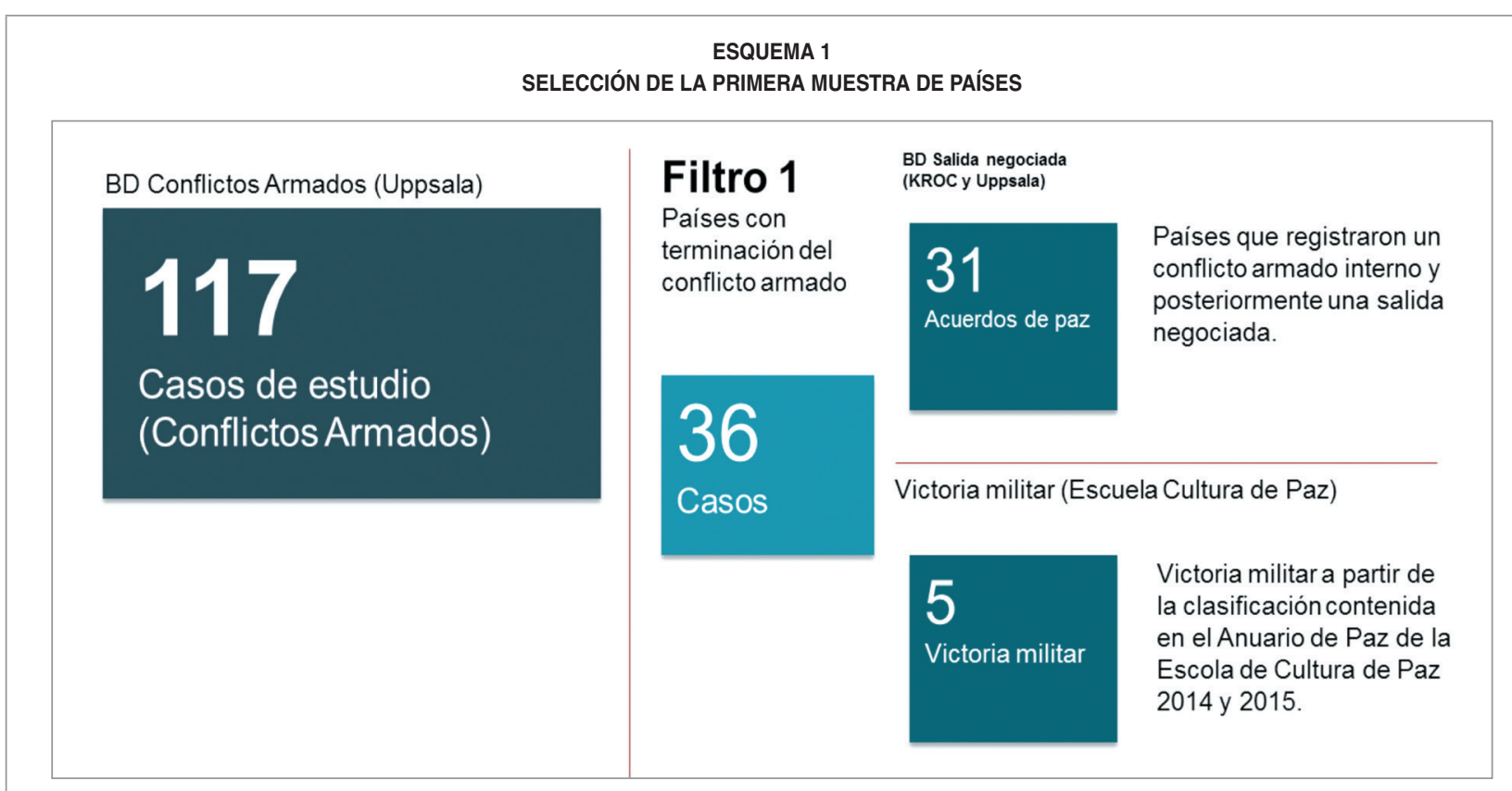

Fuente: Departamento Nacional de Planeación, Colombia.

\subsection{Anuarios de Paz de la Escuela de Paz de España}

El Anuario de Procesos de Paz es una publicación anual editada desde 2006. En la publicación se analizan los procesos de negociación para la terminación de conflictos armados internos proponiendo tres tipologías de resolución: acuerdo de paz, fin sin negociación y victoria militar. Adicionalmente, a través del seguimiento en los medios, la base provee perfiles detallados de cada proceso que se dividen en cinco categorías: bien, con dificultades, mal, en exploración y resueltos.

\subsection{Selección de las muestras}

Primera muestra. Del total de los 117 países identificados en la fuente de Uppsala se cruzó información con la base de datos del Kroc Institute y con las dos últimas versiones del Anuario de Paz (2014-2015). De este cruce de fuentes se obtuvo una muestra de 36 países: 31 países con acuerdo de paz y cinco países con victoria militar. Esta muestra involucra países con terminación del conflicto, es decir, países que han alcanzado etapas de posconflicto por medio de un acuerdo de paz o un proceso de victoria militar. De esta manera se garantizó que se incluyeran países como Perú, que, a pesar de no contar con un acuerdo de paz, puede proveer elementos interesantes en el análisis económico del posconflicto.

Segunda muestra. Recoge los 31 países de la primera muestra que tuvieron una salida negociada al conflicto. Son países que han vivido conflictos con variables étnicas, religiosas y sociales que no necesariamente han tenido presencia en Colombia, pero cuyos acuerdos de paz contemplaron componentes que se discuten actualmente en La Habana, tales como desarme, desmovilización y reintegración.

Tercera muestra. Partiendo de la segunda muestra, y con el fin de acotar aún más los países para el ejercicio comparativo, se $\triangleright$ 
S. Gaviria Muñoz, L. F. Mejía Alzate, G. Piraquive Galeano, G. Cifuentes Ghidini, R. López López y Y. Parra Vera

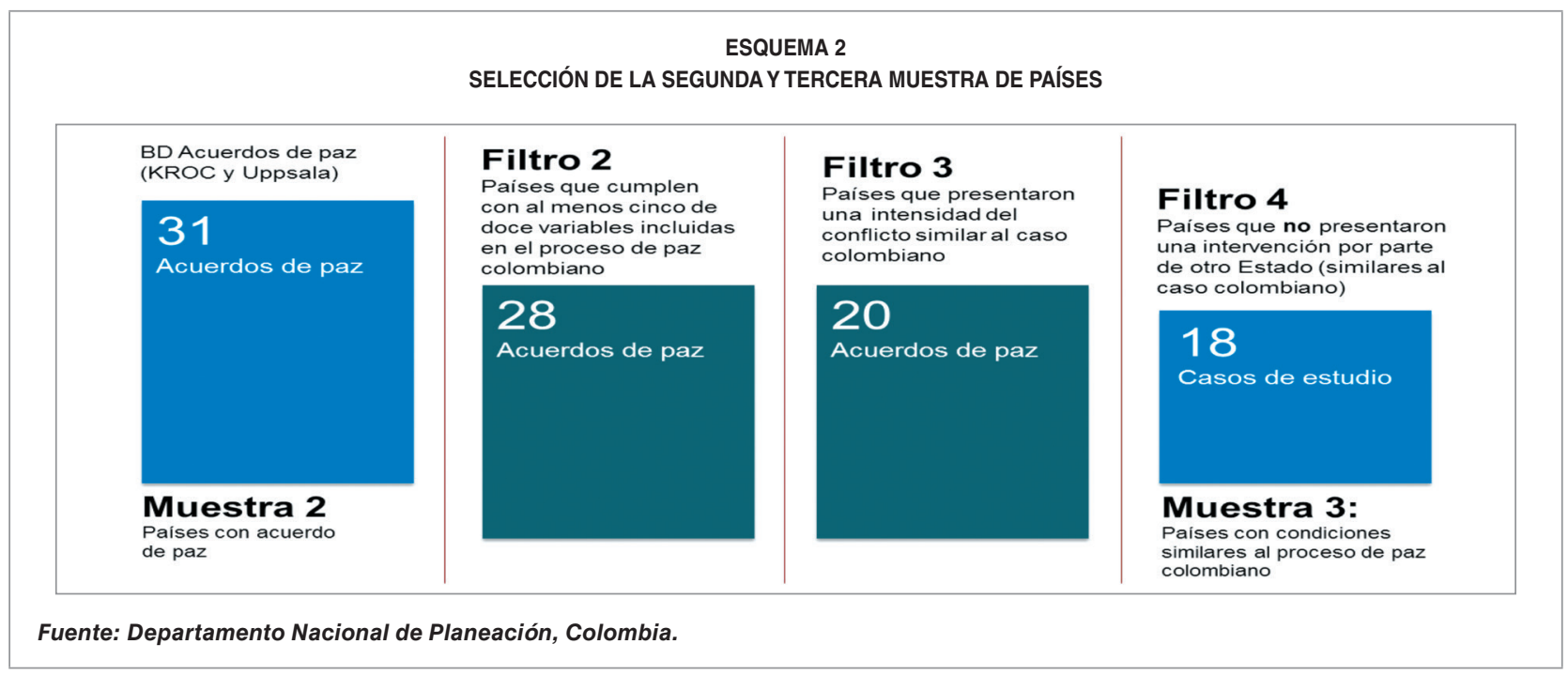

revisaron las 51 variables que forman parte de la Peace Accords Matrix y se seleccionaron doce. El criterio de selección fue principalmente la coincidencia de variables disponibles en la base de datos frente a las características del proceso de conversaciones de paz que se adelanta en Colombia con las FARC-EP. Las doce variables seleccionadas fueron: 1) proceso de desarme; 2) proceso de desmovilización; 3) proceso de reintegración; 4) comisión de la verdad; 5) reparación a víctimas; 6) reforma electoral; 7) mecanismo de ratificación del acuerdo; 8) reformas en torno al desarrollo; 9) tiempo definido de implementación del acuerdo; 10) apoyo $\triangleright$

TABLA 1

PAÍSES CON TERMINACIÓN DEL CONFLICTO ARMADO (36)

\begin{tabular}{|l|c|}
\hline \multicolumn{1}{|c|}{ País } & Fecha \\
\hline Angola & Abr/02 \\
Bosnia & Nov/95 \\
Camboya & Oct/91 \\
Costa de Marfil & Mar/07 \\
El Salvador & Dic/91 \\
Guatemala & Dic/96 \\
India & Feb/93 \\
Irlanda del Norte (Reino Unido) & Abr/98 \\
Liberia & Ago/03 \\
Macedonia & $\mathrm{Ago} / 01$ \\
Mozambique & Oct/92 \\
Níger & $\mathrm{Abr} / 95$ \\
Perú* & 1992 \\
Ruanda & $\mathrm{Ago} / 93$ \\
Sierra Leona & $\mathrm{Jul} / 99$ \\
Sudáfrica & $\mathrm{Nov} / 93$ \\
Tayikistán & Jun/97 \\
Yemen* & 2011 \\
Bangladés & Dic/97 \\
\hline
\end{tabular}

\begin{tabular}{|l|c|}
\hline \multicolumn{1}{|c|}{ País } & Fecha \\
\hline Burundi & Ago/00 \\
Congo (Brazzaville) & Dic/99 \\
Croacia & Nov/95 \\
Filipinas & Sep/96 \\
Guinea-Bissau & Nov/98 \\
Indonesia & Ago/05 \\
Líbano & Oct/89 \\
Libia* & 2011 \\
Malí & Ene/91 \\
Nepal & Nov/06 \\
Papúa-Nueva Guinea & Ago/01 \\
Rep. Centroafricana* & 2013 \\
Senegal & Dic/04 \\
Sri Lanka* & 2009 \\
Sudán & Ene/05 \\
Timor-Leste (Timor Oriental) & May/99 \\
Yibuti & May/01 \\
\hline *Países con victoria militar. & \\
Fuente: Departamento Nacional de Planeación, Colombia. \\
\hline
\end{tabular}


de donantes; 11) presencia de otros grupos armados al margen de la ley; y 12) cese al fuego.

Con base en estas doce variables se aplica un filtro para seleccionar los países que cumplieran al menos 5 de las 12 mencionadas, resultando una muestra de 28 países. Adicionalmente, se revisaron cuáles de esos 28 compartían la misma intensidad del conflicto con Colombia, resultando una muestra de 20 países. Finalmente, se filtraron y descartaron aquellos países que habían tenido la intervención de un tercer Estado, dando lugar a una muestra final de 18 países. Esta lista busca delimitar la muestra a aquellos países con mayores similitudes al caso colombiano, en términos de la naturaleza de los acuerdos que se firmaron y su coincidencia con los puntos de la agenda de negociación de La Habana.

A continuación, se relacionan los países seleccionados para el ejercicio comparativo. En el caso de la segunda lista, los países son los mismos de la primera muestra, pero excluyendo aquellos países con victoria militar.

TABLA 2

PAÍSES CON CONDICIONES SIMILARES AL CASO COLOMBIANO (18)

\begin{tabular}{|l|c|}
\hline \multicolumn{1}{|c|}{ País } & Fecha \\
\hline Bangladés & Dic/97 \\
Camboya & Oct/91 \\
Filipinas & Sep/96 \\
India & Feb/93 \\
Irlanda del Norte (Reino Unido) & $\mathrm{Abr} / 98$ \\
Macedonia & $\mathrm{Ago} / 01$ \\
Níger & $\mathrm{Abr} / 95$ \\
Ruanda & $\mathrm{Ago} / 93$ \\
Sudáfrica & $\mathrm{Nov} / 93$ \\
Burundi & $\mathrm{Ago} / 00$ \\
Costa de Marfil & $\mathrm{Mar} / 07$ \\
Guatemala & $\mathrm{Dic} / 96$ \\
Indonesia & $\mathrm{Ago} / 05$ \\
Liberia & $\mathrm{Ago} / 03$ \\
Malí & $\mathrm{Abr} / 92$ \\
Papúa-Nueva Guinea & $\mathrm{Ago} / 01$ \\
Senegal & $\mathrm{Dic} / 04$ \\
Yibuti & $\mathrm{May} / 01$ \\
\hline Fuente: Departamento Nacional de Planeación, Colombia. \\
\hline
\end{tabular}

\section{Análisis de los resultados}

En esta sección se describen de forma breve los resultados de las estimaciones efectuadas sobre las principales variables para calcular el dividendo de la paz sobre las 16 variables macroeconómicas estudiadas: crecimiento económico, PIB per cápita, inversión, ahorro, inversión extranjera directa, inflación, desempleo, ingresos y gastos del Gobierno, grado de apertura comercial, exportaciones e importaciones, consumo de los hogares y crecimiento de la agricultura, la industria y la construcción.

El análisis se realizó en seis periodos de tiempo: el año del acuerdo de cada país, 3 y 5 años antes del mismo, y 3, 5 y 10 años después de dicho acuerdo. Esto con el fin de tener una perspectiva de corto, mediano y largo plazo sobre la evolución de las distintas variables. Así las cosas, el dividendo de la paz resulta de la diferencia entre el promedio de los datos calculados 3 y 5 años antes del acuerdo y el promedio de los datos calculados 3, 5 y 10 años después del acuerdo. Este dividendo se calculó para cada agrupación de países y para cada variable ${ }^{1}$.

\section{Producto interior bruto}

En términos del PIB, los datos indican que cinco años antes del acuerdo las economías registraron tasas de crecimiento dinámicas, probablemente derivadas del efecto multiplicador del gasto militar. En el año del acuerdo, las tasas reportadas fueron negativas o cercanas a cero, posiblemente como resultado $\triangleright$

\footnotetext{
1 Por ejemplo, en el caso del cálculo del PIB, el promedio de las tasas de crecimiento 5 y 3 años antes de la consecución del acuerdo para los 36 países con terminación del conflicto fue de 3,7 por 100, mientras que el promedio de las tasas de crecimiento 3,5 y 10 años después de la consecución del acuerdo para el mismo grupo de países fue de 4,9 por 100. Entonces, el dividendo de la paz sobre el crecimiento, definido como la diferencia entre el crecimiento promedio antes y después del acuerdo, es de 1,1 por 100 .
} 
S. Gaviria Muñoz, L. F. Mejía Alzate, G. Piraquive Galeano, G. Cifuentes Ghidini, R. López López y Y. Parra Vera

TABLA 3

RESUMEN DE LOS RESULTADOS OBTENIDOS

\begin{tabular}{|c|c|c|c|c|c|}
\hline \multirow{2}{*}{ Variable } & \multirow{2}{*}{$\begin{array}{c}\text { Unidad } \\
\text { de medida }\end{array}$} & \multirow{2}{*}{ Número de países } & \multicolumn{2}{|c|}{ Promedio } & \multirow{2}{*}{ Dividendo } \\
\hline & & & Antes del acuerdo & Después del acuerdo & \\
\hline \multirow{3}{*}{ PIB } & \multirow{3}{*}{ Variación \% } & 36 & 3,7 & 4,9 & 1,1 \\
\hline & & 31 & 3,4 & 5,0 & 1,6 \\
\hline & & 18 & 3,1 & 4,9 & 1,9 \\
\hline \multirow{3}{*}{ PIB per cápita } & \multirow{3}{*}{$\begin{array}{l}\text { USD } \\
\text { corrientes }\end{array}$} & 36 & $1.663,0$ & $2.848,0$ & $1.185,0$ \\
\hline & & 31 & $1.348,0$ & $2.811,0$ & $1.463,0$ \\
\hline & & 18 & $1.719,0$ & $3.628,0$ & $1.909,0$ \\
\hline \multirow{3}{*}{ Inversión } & \multirow{3}{*}{$\%$ del PIB } & 36 & 17,2 & 22,0 & 4,9 \\
\hline & & 31 & 16,6 & 21,9 & 5,3 \\
\hline & & 18 & 16,4 & 21,9 & 5,5 \\
\hline \multirow{3}{*}{ Ahorro } & \multirow{3}{*}{$\%$ del PIB } & 36 & 15,9 & 16,9 & 1,0 \\
\hline & & 31 & 14,1 & 16,9 & 2,8 \\
\hline & & 18 & 15,2 & 17,6 & 2,4 \\
\hline \multirow{3}{*}{ IED } & \multirow{3}{*}{$\%$ del PIB } & 36 & 1,2 & 4,3 & 3,1 \\
\hline & & 31 & 1,0 & 4,6 & 3,7 \\
\hline & & 18 & 0,8 & 4,1 & 3,3 \\
\hline \multirow{3}{*}{ Inflación } & \multirow{3}{*}{ Variación \% } & 36 & 53,4 & 10,3 & $-43,1$ \\
\hline & & 31 & 60,9 & 10,5 & $-50,5$ \\
\hline & & 18 & 6,7 & 6,2 & $-0,5$ \\
\hline \multirow{3}{*}{ Desempleo } & \multirow{3}{*}{ Variación \% } & 36 & 14,3 & 14,0 & $-0,3$ \\
\hline & & 31 & 16,2 & 15,7 & $-0,5$ \\
\hline & & 18 & 17,0 & 15,7 & $-1,3$ \\
\hline \multirow{3}{*}{$\begin{array}{l}\text { Ingresos del } \\
\text { Gobierno }\end{array}$} & \multirow{3}{*}{$\%$ del PIB } & 36 & 21,9 & 23,2 & 1,3 \\
\hline & & 31 & 19,9 & 22,7 & 2,7 \\
\hline & & 18 & 20,5 & 21,9 & 1,4 \\
\hline & & 36 & 21,6 & 25,7 & 4,0 \\
\hline $\begin{array}{l}\text { Gastos del } \\
\text { Gobierno }\end{array}$ & $\%$ del PIB & 31 & 21,1 & 24,1 & 3,0 \\
\hline & & 18 & 22,1 & 24,2 & 2,1 \\
\hline & & 36 & 106,5 & 122,4 & 15,9 \\
\hline $\begin{array}{l}\text { Apertura del } \\
\text { Comercio }\end{array}$ & $\%$ del PIB & 31 & 114,2 & 129,2 & 14,9 \\
\hline & & 18 & 56,7 & 74,4 & 17,7 \\
\hline & & 36 & 44,9 & 49,3 & 4,4 \\
\hline Exportaciones & $\%$ del PIB & 31 & 47,3 & 51,3 & 4,0 \\
\hline & & 18 & 27,4 & 33,8 & 6,4 \\
\hline & & 36 & 58,8 & 74,4 & 15,6 \\
\hline Importaciones & $\%$ del PIB & 31 & 63,7 & 79,4 & 15,7 \\
\hline & & 18 & 29,3 & 40,6 & 11,2 \\
\hline & & 36 & 5,5 & 7,4 & 1,9 \\
\hline $\begin{array}{l}\text { Consumo de los } \\
\text { hogares }\end{array}$ & Variación \% & 31 & 5,1 & 7,6 & 2,5 \\
\hline & & 18 & 6,3 & 6,9 & 0,6 \\
\hline & & 36 & 5,3 & 6,5 & 1,2 \\
\hline Agricultura & Variación \% & 31 & 5,5 & 6,7 & 1,2 \\
\hline & & 18 & 3,9 & 5,3 & 1,4 \\
\hline & & 36 & 5,5 & 6,2 & 0,7 \\
\hline Industria & Variación \% & 31 & 5,2 & 6,3 & 1,1 \\
\hline & & 18 & 4,9 & 5,7 & 0,8 \\
\hline & & 36 & 4,3 & 9,7 & 5,3 \\
\hline Construcción & Variación \% & 31 & 3,7 & 10,4 & 6,7 \\
\hline & & 18 & 5,3 & 9,6 & 4,4 \\
\hline
\end{tabular}




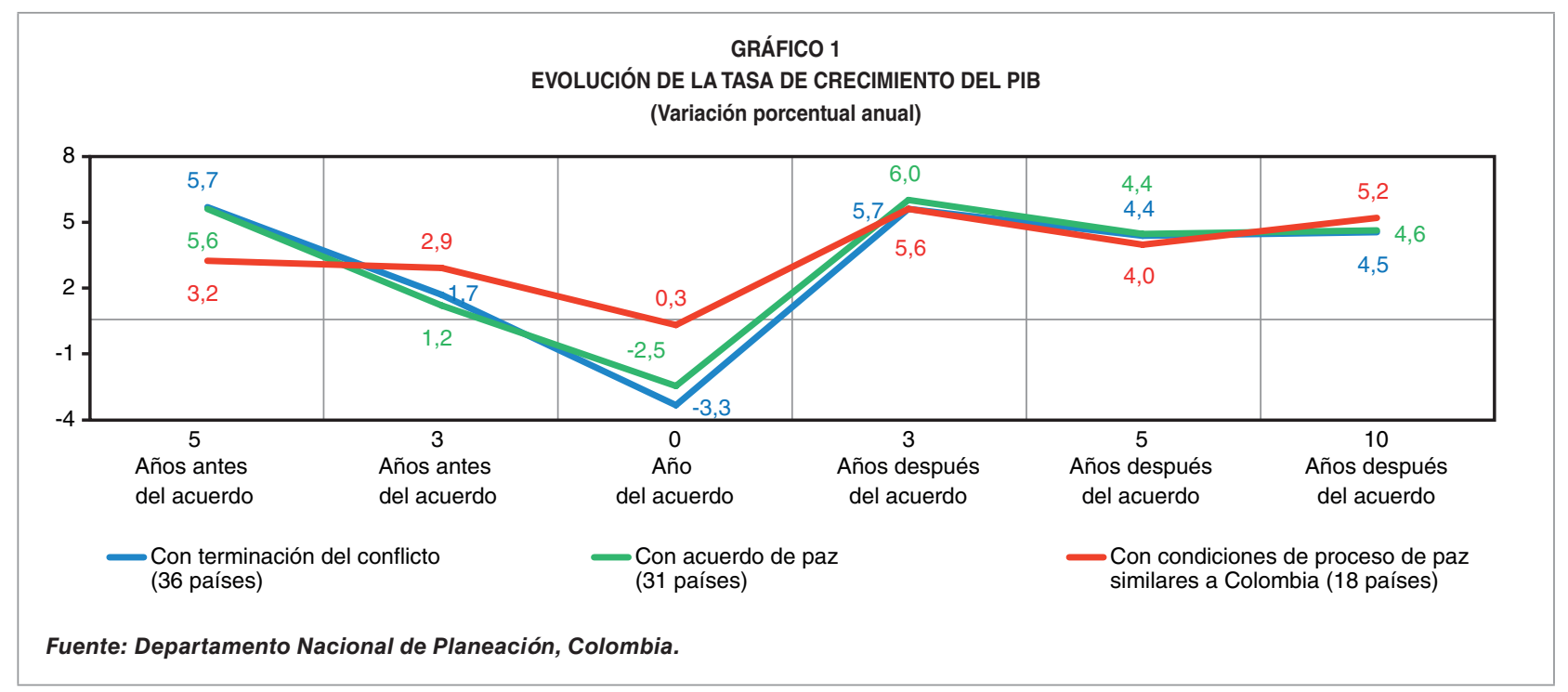

del resquebrajamiento económico a causa del conflicto y, una vez firmado el acuerdo, estas repuntaron con un efecto especialmente significativo en los primeros años después del suceso (Gráfico 1).

Al estimar el dividendo entre los años que precedieron al acuerdo y los que le siguieron se obtuvo que, en promedio, los países registraron tasas de crecimiento adicionales de entre 1,1 y 1,9 puntos del PIB. La estimación más alta es para los países cuyo proceso de paz cuenta con condiciones similares al de
Colombia y la más baja corresponde a los países con terminación del conflicto. La muestra de los países con terminación del conflicto negociado a través de un acuerdo de paz se ubicó en la mitad, con un aumento en promedio de 1,6 puntos del PIB.

\section{Tasa de inversión}

El efecto de la paz sobre la inversión total es significativo, posiblemente por el mayor nivel de confianza que este genera en los $\triangleright$

GRÁFICO 2

EVOLUCIÓN DE LA INVERSIÓN

(Porcentaje del PIB)

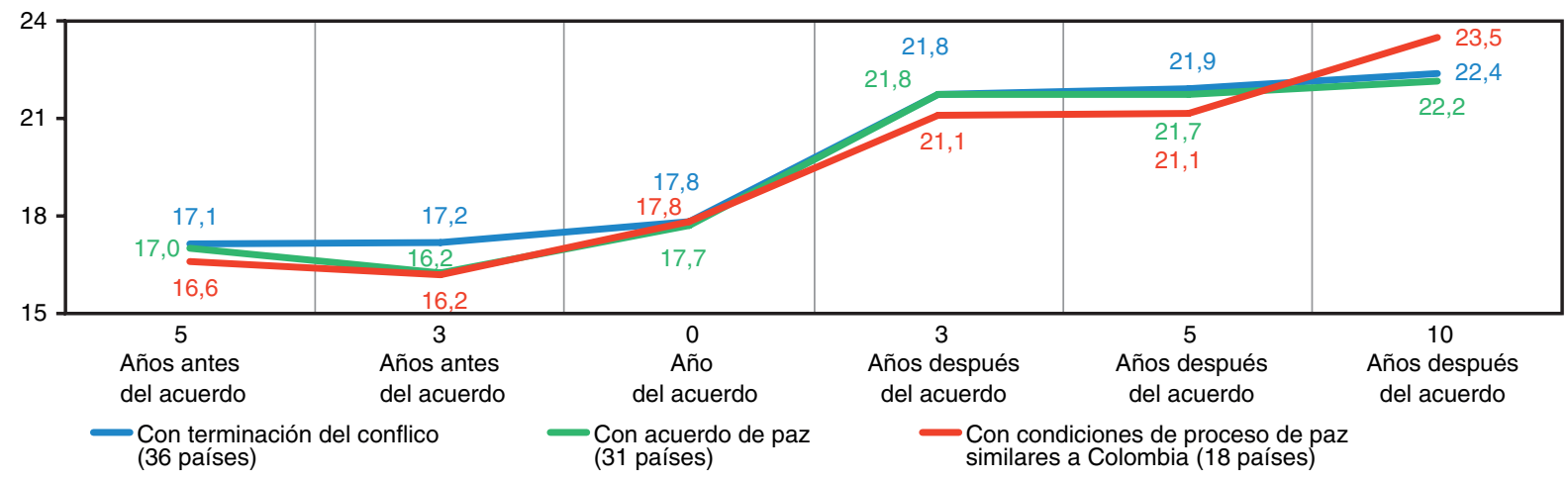

Fuente: Departamento Nacional de Planeación, Colombia. 


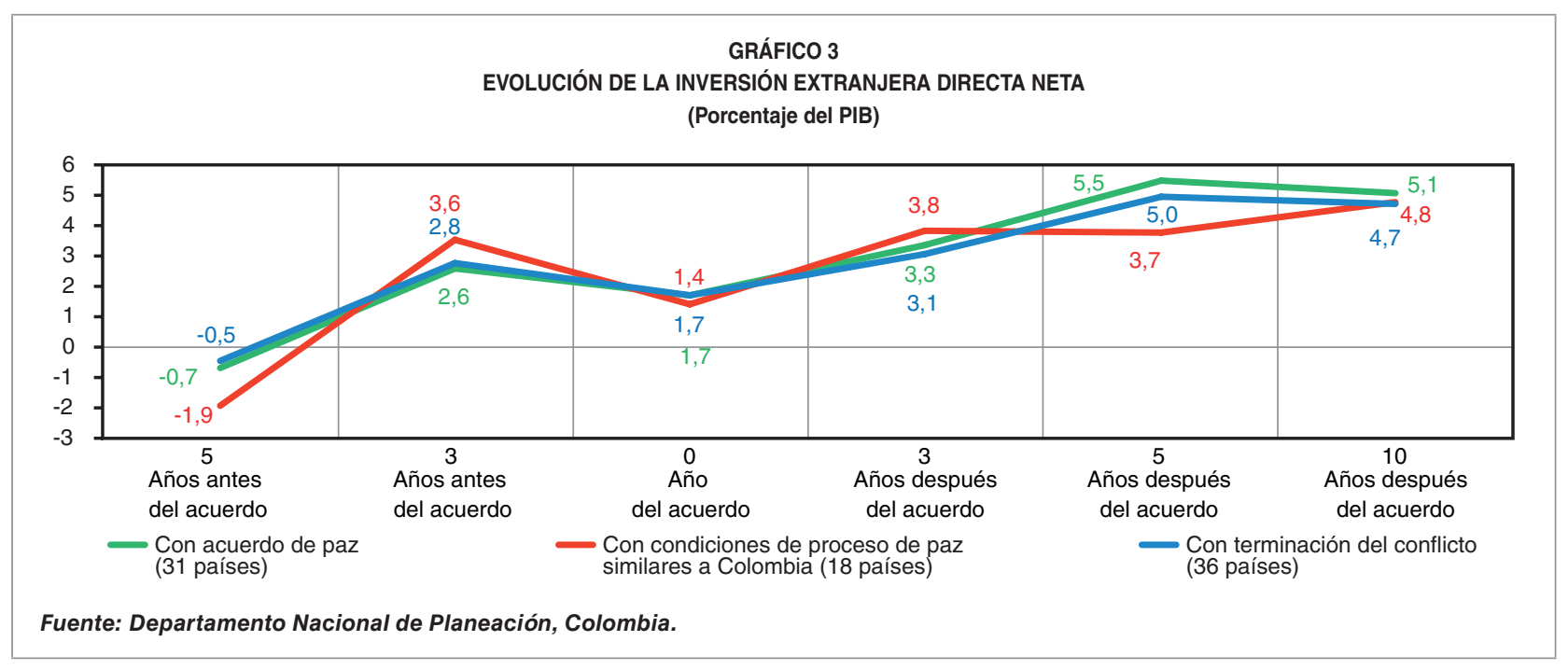

inversionistas. Para calcularlo se utilizaron los datos correspondientes a la relación inversión/ PIB anual de los países. Los resultados revelan dos tendencias generalizadas: por un lado, las economías registraron tasas de crecimiento de la inversión más altas que la del PIB; por el otro, la relación inversión/PIB aumentó de forma importante después de la consecución del acuerdo de paz, particularmente en los tres años siguientes (Gráfico 2).

En términos del dividendo de la paz, la estimación indica que, en promedio, los países registraron tasas de inversión superiores al 30 por 100. La inversión/PIB creció, respectivamente, en 4,9; 5,3 y 5,5 puntos porcentuales del PIB en los países con terminación del conflicto, los que lo hicieron a través de un acuerdo de paz y aquellos cuyo proceso de paz cuenta con condiciones similares al de Colombia.

\section{Inversión extranjera directa (IED)}

No es de extrañar que el efecto de la paz sobre la inversión extranjera directa neta sea también positivo. Los datos muestran que a pesar de que la relación IED/PIB anual de los países alcanzó uno de sus niveles más bajos en el momento del acuerdo, una vez terminado el conflicto esta variable tuvo un comportamiento creciente y sostenido (Gráfico 3). El efecto se puede explicar como una respuesta al incremento de la confianza que estos acuerdos suelen generar en el inversionista extranjero.

El rango del impacto se encuentra entre un incremento del 3,1 (países con terminación del conflicto) y 3,7 puntos porcentuales del PIB (países cuyo proceso de paz cuenta con condiciones similares al de Colombia). Para el grupo de países con terminación del conflicto negociado a través de un acuerdo de paz el efecto es de 3,3. Adicionalmente, se observa que, diez años después del establecimiento del acuerdo, la relación IED/PIB casi se triplicó en todos los grupos de países.

\section{Desempleo}

El efecto de la paz sobre el mercado laboral es el de una disminución leve pero sostenida del desempleo. Sin embargo, si se compara con el nivel de desempleo registrado durante la consecución del acuerdo (Gráfico 4), para todos los grupos de países, la disminución en la tasa de desempleo anual de los países $D$ 


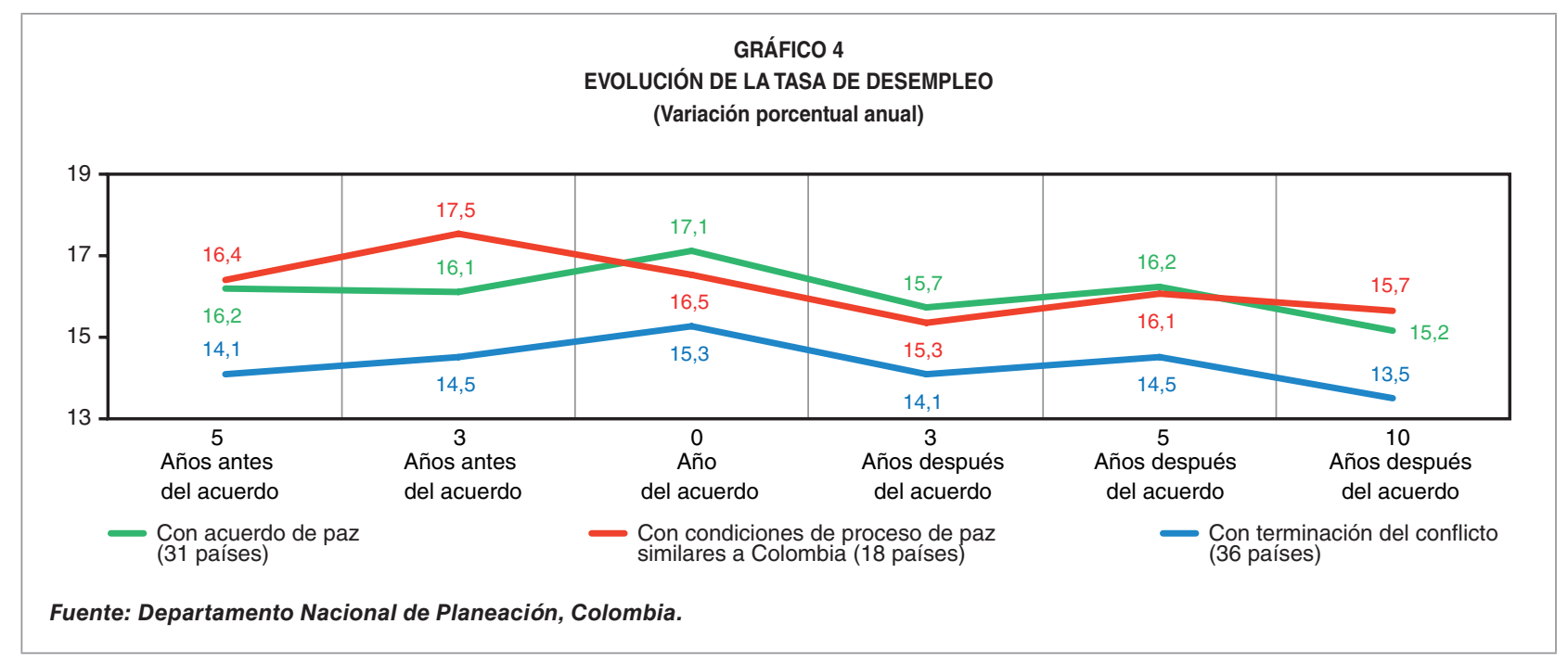

es aún más notoria. El comportamiento de esta variable es consistente con la mejora de las demás variables macroeconómicas descritas anteriormente.

El dividendo de la paz representa una reducción en la tasa de desempleo de entre 0,3 (países con terminación del conflicto) y 1,3 puntos porcentuales (países cuyo proceso de paz cuenta con condiciones similares al de Colombia). Para los países con terminación del conflicto negociado a través de un acuerdo de paz la cifra es de 0,5 . Se observa que la reducción del desempleo fue cercana al 9 por 100 después de diez años del establecimiento del acuerdo para los países cuyo proceso de paz tiene condiciones similares al de Colombia.

\section{Exportaciones}

Esta variable muestra un comportamiento algo distinto al de la de apertura comercial. En los cinco años anteriores al acuerdo las economías registraron exportaciones crecientes. Sin embargo, una vez firmado, la tasa de exportaciones sobre el PIB muestra un leve descenso en los primeros tres años como $D$

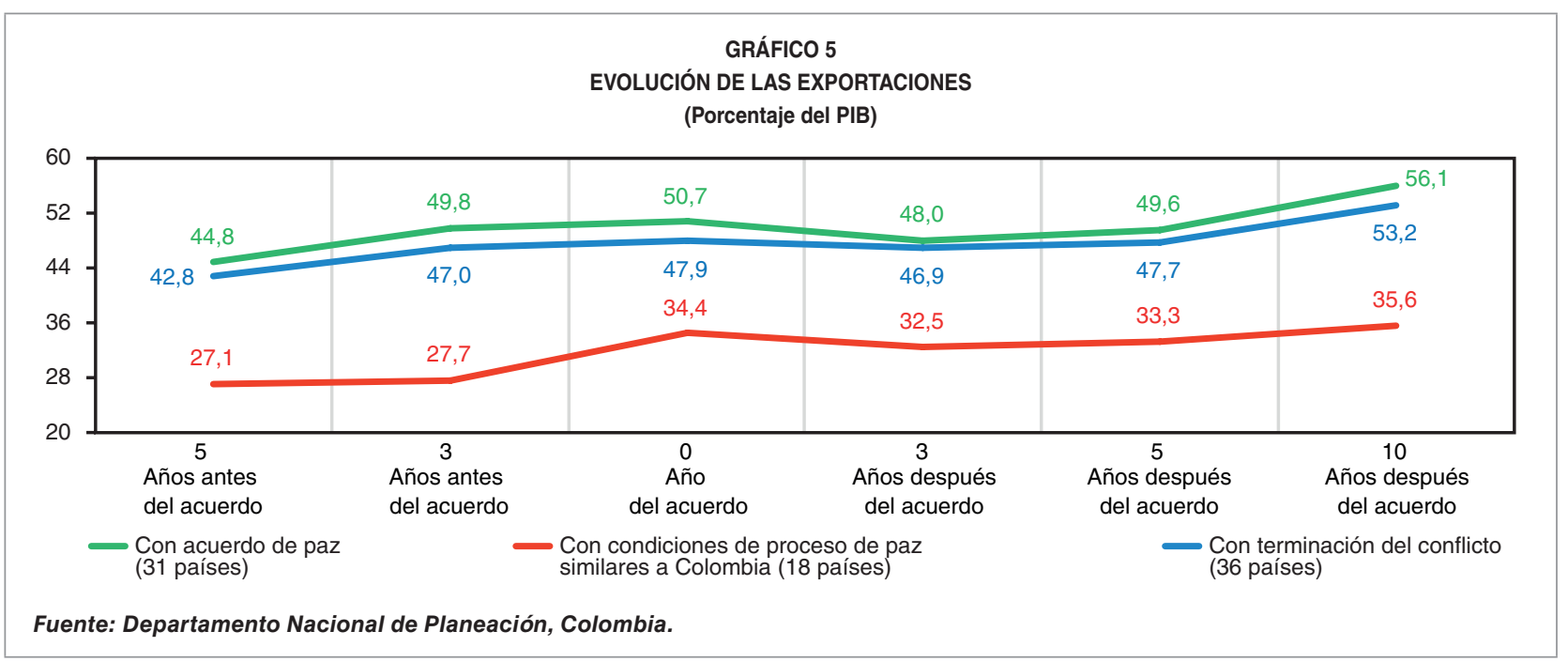


consecuencia del proceso de recuperación, reconversión productiva y definición de una nueva oferta exportadora en el postconflicto. Pasados los tres años, la tendencia es que el nivel de exportaciones sobre el PIB de los países repunte y se consolide diez años después del acuerdo.

El rango del cambio está entre 4,0 (países con terminación del conflicto negociado a través de un acuerdo de paz) y 6,4 (países cuyo proceso de paz cuenta con condiciones similares al de Colombia) puntos de aumento en las exportaciones como porcentaje del PIB. En medio se encuentran los países con terminación del conflicto, que muestran un aumento de 4,4 puntos.

\section{Agricultura}

El efecto de la paz sobre la agricultura, medido como las tasas de variación porcentual anuales del sector, muestra una imagen similar a la del consumo de los hogares. Entre los cinco y tres años antes del acuerdo, las economías registran una tasa de crecimiento positiva pero decreciente en el sector, que llega a variaciones negativas en el año del acuerdo. Esto en tanto que el sector agrícola se ve afectado por la baja producción y la destrucción ambiental fruto del conflicto. Firmado el acuerdo, el sector repunta alcanzando un crecimiento importante en los primeros tres años como consecuencia de un aumento en la productividad del sector. Entre los cinco y diez años después del acuerdo, la tasa se estabiliza y se mantiene en un nivel moderado y sostenible.

El impacto del dividendo de la paz en el sector agricultura se estima entre 1,2 y 1,4 pp adicionales en la tasa de crecimiento. El cambio de menor magnitud se da en los dos grupos de países con terminación del conflicto y con terminación del conflicto negociado a través de un acuerdo de paz. Los países cuyo proceso de paz cuentan con condiciones similares al de Colombia evidencian el cambio de mayor orden.

\section{Industria}

El efecto de la paz en la industria sigue un patrón similar al del sector de agricultura. Al medir la variación porcentual anual de las tasas de crecimiento del sector para los diferentes países, se encuentra que, si bien en promedio estas son crecientes antes de la firma, hay una desaceleración fuerte al llegar el momento $D$

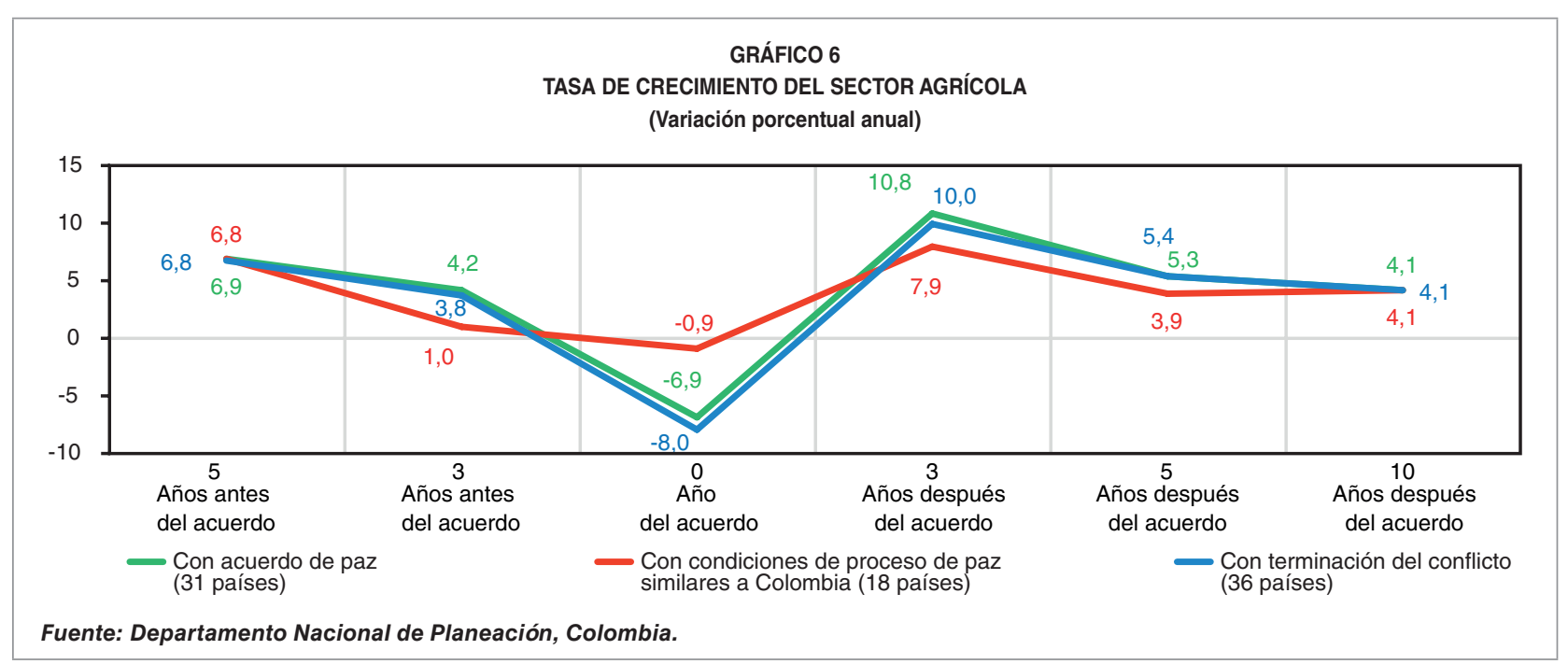


GRÁFICO 7

TASA DE CRECIMIENTO DEL SECTOR INDUSTRIA

(Variación porcentual anual)

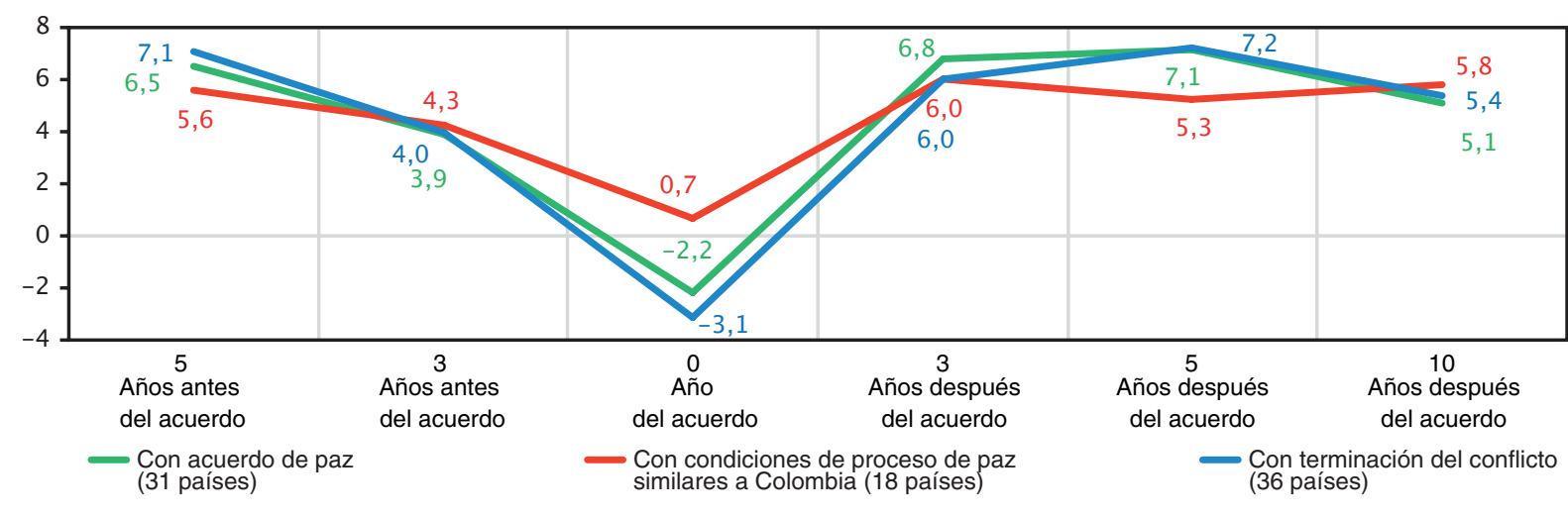

Fuente: Departamento Nacional de Planeación, Colombia.

de la terminación del conflicto. Tres años después de la firma, el sector industrial presenta una recuperación importante gracias a que la reconstrucción de los países suele generar un aumento en la demanda del sector y al efecto de encadenamiento del mismo. Finalmente, a los diez años del acuerdo se consolida un crecimiento sostenible de la industria (Gráfico 7).

El orden de magnitud del cambio para la industria es ligeramente inferior al del sector agrario, pues se calcula un aumento en la tasa que está entre 0,7 puntos porcentuales (países con terminación del conflicto) y 1,1 (terminación del conflicto negociado a través de un acuerdo de paz). En el medio están los países cuyo proceso de paz cuenta con condiciones similares al de Colombia, con una estimación de 0,8 puntos porcentuales.

\section{Construcción}

El comportamiento de las tasas de variación porcentual anuales de los países en el sector de la construcción es similar a los de agricultura e industria. Entre los cinco y tres años antes del acuerdo, las economías registraron $\triangleright$

GRÁFICO 8

TASA DE CRECIMIENTO DEL SECTOR CONSTRUCCIÓN

(Variación porcentual anual)

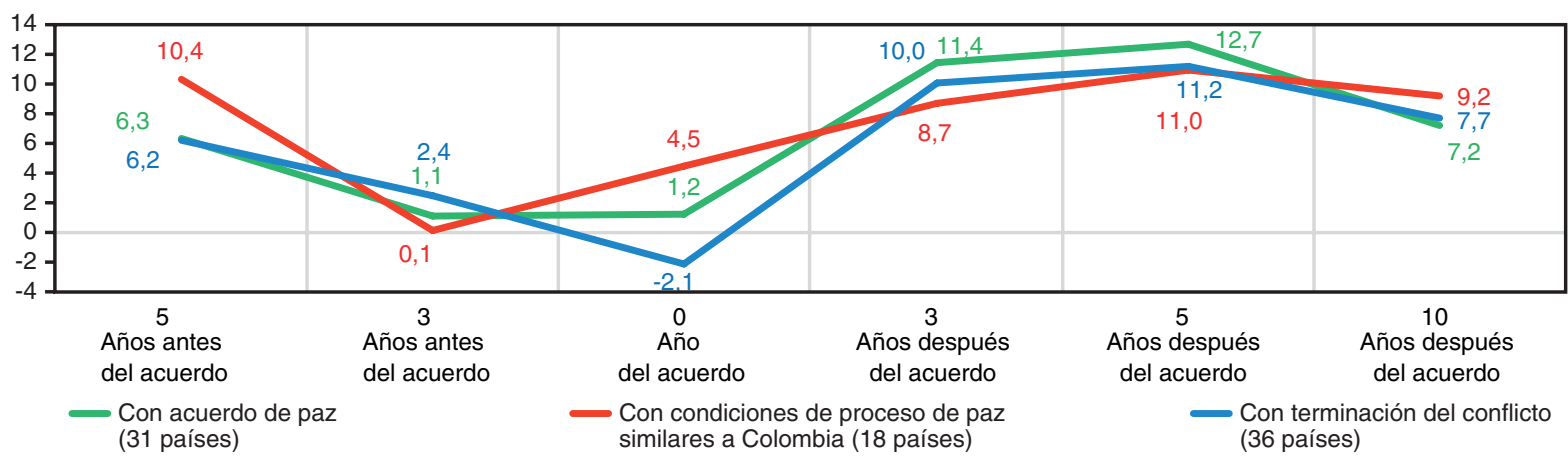

Fuente: Departamento Nacional de Planeación, Colombia. 
una tasa de crecimiento positiva pero decreciente, llegando a su punto más bajo en el año del acuerdo. Una vez finalizado el conflicto, el sector presenta una recuperación importante en los primeros tres años, motivada por la necesidad de reconstruir la infraestructura deteriorada por la guerra (Gráfico 8). Finalmente, entre cinco y diez años después del acuerdo, las tasas, si bien disminuyen ligeramente, se consolidan en niveles todavía altos.

En términos de su magnitud, el impacto del dividendo de la paz es mayor en la construcción que en los otros sectores analizados. Las tasas presentan aumentos de entre 4,4 puntos porcentuales (países cuyo proceso de paz cuenta con condiciones similares al de Colombia) y 6,7 (países con terminación del conflicto negociado a través de un acuerdo de paz). Los del grupo de países con terminación del conflicto obtienen un valor de 5,3 puntos porcentuales.

\section{Conclusiones}

El ejercicio presentado en este trabajo tuvo como objetivo presentar un análisis detallado sobre el dividendo económico que deja un proceso de paz con base en la experiencia de otros países, lo que permite dar elementos adicionales a la discusión sobre cuál sería el efecto del proceso de paz sobre la economía colombiana. El resultado central del trabajo es que el dividendo económico de la paz (medido como la diferencia entre el promedio de los datos calculados 3 y 5 años antes del acuerdo y el promedio de los datos calculados 3, 5 y 10 años después del acuerdo) se encuentra entre 1,1 y 1,9 puntos porcentuales adicionales de crecimiento en el PIB, así como en un incremento en diez años del 54 por 100 en el PIB per cápita sin incluir el componente tendencial.

Por el lado de la demanda, la mayor confianza sobre las economías postconflicto genera un aumento de 2,5 puntos porcentuales en la tasa de crecimiento del consumo de los hogares, conduce a un incremento de 5,5 puntos en la inversión como porcentaje del PIB, permite que la inversión extranjera directa se triplique e inserta de forma considerable las economías en el comercio internacional al aumentar en 17,7 puntos la tasa de apertura comercial (suma de exportaciones e importaciones como porcentaje del PIB).

Por el lado de la oferta, los resultados muestran un crecimiento de 1,4 puntos porcentuales adicionales en el sector agropecuario, un aumento de 0,8 pp en la tasa de crecimiento de la industria y un destacable aumento de 4,4 pp en el crecimiento del sector de la construcción, que parece beneficiarse de forma especial de las necesidades de infraestructura que surgen una vez finaliza el conflicto armado.

Una extrapolación de estos resultados al caso colombiano implica, entre otras cifras, que 1) el crecimiento potencial de la economía aumentaría del 3,5 por 100 a niveles cercanos al 5 por 100; 2) el PIB per cápita pasaría de 6.000 dólares a niveles cercanos a los 12.000 dólares; 3) la tasa de inversión aumentaría del 28 al 34 por 100 del PIB; 4) la inversión extranjera directa aumentaría de 12.000 a 35.000 millones de dólares anuales; y 5) las exportaciones alcanzarían niveles del orden de 65.000 millones de dólares, frente a los 35.000 millones de dólares de hoy. Estos resultados permiten afirmar que el dividendo económico de la firma de la paz en el caso colombiano podría ser significativo y afectar de manera positiva al bienestar de todos los colombianos. 


\section{Bibliografía}

[1] ÁlvareZ, S. y RetTBERG, A. (2008). «Cuantificando los efectos económicos del conflicto: Una exploración de los costos y los estudios sobre los costos del conflicto armado colombiano». Colombia Internacional, n. .67 .

[2] ARIAS, M. e IBÁÑEZ, A. (2014). «Agricultural Production Amid Conflict: The Effects of Shocks, Uncertainty, and Governance of NonState Armed Actors". Documento CEDEUniversidad de los Andes.

[3] COLECTIVO DE ORGANIZACIONES SOCIALES, COS. (2006). Guatemala a 10 años de la firma de los Acuerdos de Paz. Guatemala.

[4] DEPARTMENT OF PEACE AND CONFLICT RESEARCH (2015). (Base de datos). Uppsala, Suecia. Universidad de Uppsala. UCDP/PRIO Armed Conflict Dataset v.4-2015, 1946-2014.

[5] FISAS, V. (2014). Anuario de Procesos de Paz. Barcelona: Icaria.

[6] FISAS, V. (2015). Anuario de Procesos de Paz. Barcelona: Icaria.

[7] GONZÁLEZ, A, (2006). «Convergencia regional y conflicto armado interno en Colombia 1980-2004». Tesis de economía. Pontificia Universidad Javeriana.

[8] HOEFFLER, P. C. (2002). The World Bank. Development Research Group.

[9] IBÁÑEZ, A. (2008). El impacto del desplazamiento forzoso en Colombia. Cepal. 2008.

[10] INSTITUTO UNIVERSITARIO DE OPINIÓN PÚBLICA. UNIVERSIDAD CENTROAMERICANA JOSÉ SIMEÓN CAÑAS (1998).
La violencia en El Salvador en los años noventa. Magnitud, costos y factores posibilitadores. San Salvador.

[11] NASI, C. (2008). Cuando callan los fusiles: impacto de la paz negociada en Colombia y en Centroamérica. Bogotá: Norma.

[12] QUERUBíN, P. (2003). «Crecimiento departamental y violencia criminal en Colombia». Universidad de los Andes. Documento CEDE n. 12.

[13] RETTBERG, A. (2008). Explorando el dividendo de la paz: Percepción de los impactos del conflicto en el sector privado colombiano. International Alert, Universidad de los Andes.

[14] SALAMANCA, S.; ROJAS, N. y HERNÁNDEZ, G. (2013). «Crecimiento y conflicto armado en Colombia». Archivos de Economía. DNP.

[15] UNIVERSITY OF NOTRE DAME. Peace Accords Matrix. Peace Accords Matrix. Estados Unidos. Recuperado en 2015.

[16] VARGAS, J. (2003). «Conflicto interno y crecimiento económico en Colombia». Universidad de los Andes. Tesis Maestría en Economía PEG.

[17] VILLA, E.; RESTREPO, T. y MOSCOSO, M. (2013). Crecimiento económico, conflicto armado y crimen organizado, evidencia para Colombia. Pontificia Universidad Javeriana. CERAC.

[18] BUITRAGO, W. (2015). El fantasma de la democracia en sociedades divididas por el conflicto armado interno: una aproximación a los fundamentos de los mecanismos de legitimación de acuerdos de paz. Pontificia Universidad Javeriana. 


\section{Definición de variables del Kroc Institute for International Peace Studies}

Cese del fuego. Se refiere a una paralización o suspensión de los combates; una orden militar para que cesen las acciones agresivas y movimientos; un alto el fuego puede ser una parte de un CPA o el CPA puede heredar un alto el fuego acordado previamente. Operativamente, esto mide el compromiso por parte del Gobierno y los rebeldes en el acuerdo de alto el fuego.

Desarme. La colección, la documentación y el control de las armas pequeñas, municiones, explosivos y armas ligeras y pesadas utilizadas durante la guerra.

Desmovilización. La aprobación de la gestión oficial y controlada de los combatientes activos de las fuerzas armadas $u$ otros grupos armados. La primera etapa de la desmovilización puede extenderse desde el procesamiento de los combatientes individuales en centros temporales hasta la concentración de tropas en los campos designados para este fin (lugares de acantonamiento, campamentos, zonas de concentración o cuarteles).

Reintegración. Programas por los cuales los excombatientes reciben capacitación para el trabajo, la educación o la compensación para ayudarles en su reinserción a la vida civil.

Tiempo definido de implementación del acuerdo. El acuerdo sobre la línea de tiempo por el cual se llevarán a cabo las diversas disposiciones del acuerdo de paz. Hay acuerdos que a menudo tienen múltiples líneas de tiempo para diferentes disposiciones; esta codificación se refiere a si la línea de tiempo en general fue seguida por las disposiciones señaladas.

Apoyo de donantes. El acuerdo exige un amplio apoyo financiero de Estados extranjeros u organizaciones internacionales en apoyo de la aplicación del acuerdo de paz.

Desarrollo. Las reformas o programas destinados a mejorar el desarrollo económico y social de la nación o de áreas de la nación.

Reforma electoral de partidos políticos. Las reformas o cambios en el sistema electoral que afecta a las oportunidades de participación de las personas y las partes, permitiendo que los grupos rebeldes se conviertan en partidos políticos activos.

Presencia de otros grupos armados al margen de la ley. Idioma que implica la regulación y tratamiento de los grupos paramilitares, incluyendo las milicias y los mercenarios.

Mecanismo de ratificación. El acuerdo exige un proceso por el cual se pueda conferir estatus legal formal por una legislatura o elección.

Reparaciones. El acuerdo incluye reparaciones o algún tipo de compensación que se hizo a un grupo en particular o para las víctimas del conflicto en general.

Comisión de la verdad y reconciliación. El acuerdo establece un cuerpo temporal sancionado oficialmente para investigar e informar sobre los patrones de abusos contra los derechos humanos que ocurren en el transcurso de la guerra civil. 

ISSN 0214-8307

\section{SUSCRIPCIÓN ANUAL}

\begin{tabular}{|c|c|c|c|}
\hline \multicolumn{3}{|c|}{ BOLETÍN ECONÓMICO DE INFORMACIÓN COMERCIAL ESPAÑOLA (12 NÚMEROS) } \\
\hline & $\begin{array}{c}\text { ESPAÑA } \\
\mathbf{1} \text { año }\end{array}$ & $\begin{array}{c}\text { UNIÓN EUROPEA } \\
\mathbf{1} \text { año }\end{array}$ & $\begin{array}{c}\text { RESTO DEL } \\
\text { MUNDO } \\
1 \text { año }\end{array}$ \\
\hline SUSCRIPCIÓN & $65,00 €$ & $85,00 €$ & $85,00 €$ \\
\hline $\begin{array}{c}\text { Gastos de envío } \\
\text { España }\end{array}$ & $5,76 €$ & $24,36 €$ & $30,00 €$ \\
\hline $\begin{array}{c}\text { Más 4\% de IVA. } \\
\text { Excepto Canarias, Ceuta y Melilla }\end{array}$ & $2,83 €$ & & $115,00 €$ \\
\hline TOTAL & $73,59 €$ & $109,36 €$ & \\
\hline & & & \\
\hline
\end{tabular}

\section{EJEMPLARES SUELTOS}

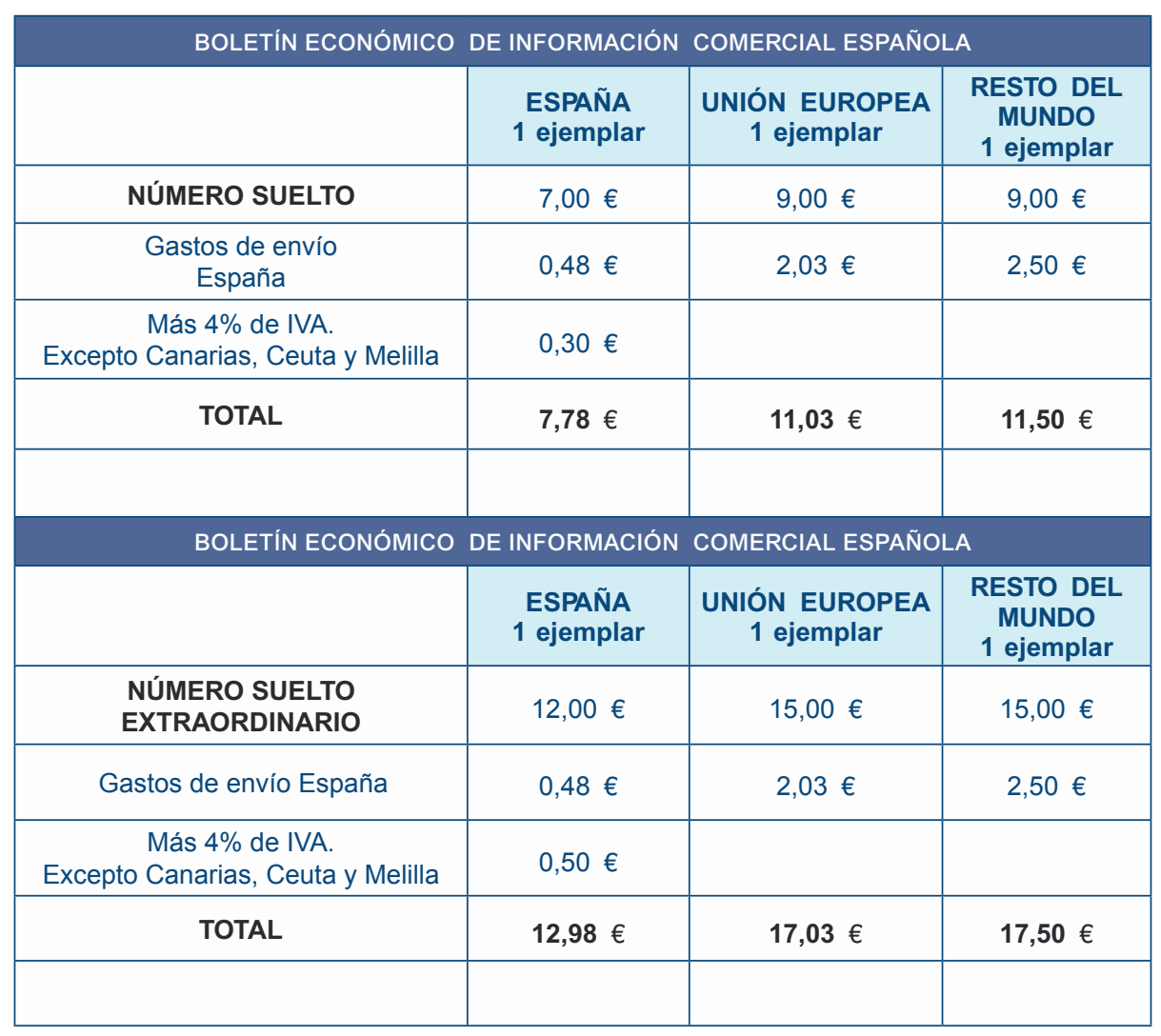

\section{DATOS}

Nombre y apellidos

Empresa

Domicilio

D.P.

N.I.F.

Teléf.

Email
DATOS DEL EDITOR:

NIF:S2800568D

Transferencia a la cuenta de ingresos por venta de publicaciones del Ministerio de Economía y Competitividad.

IBERCAJA. Calle Alcalá 29. 28014 MADRID (ESPAÑA) CÓDIGO CUENTA CLIENTE: 2085-9252-07-0330598330 CÓDIGO BIC DE IBERCAJA: CAZRES2Z

IBAN: ES47 2085-9252-07-0330598330
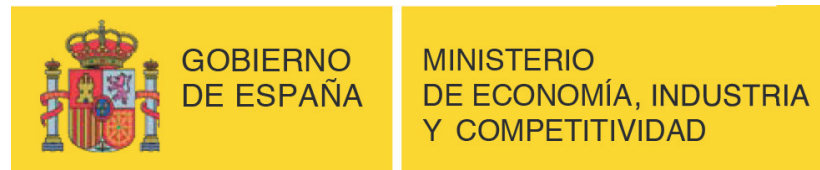


\section{NORMAS DE ESTILO DE PUBLICACIÓN}

La persona o personas interesadas en presentar un artículo para su publicación en el Boletín de Información Comercial Española (BICE) deberán enviar el artículo en formato Microsoft Word a la dirección de correo electrónico revistasice.sscc@comercio.mineco.es

El documento debe cumplir las siguientes características:

1. Ser material original no publicado ni presentado en otro medio de difusión.

2. La extensión total del trabajo (incluyendo cuadros, gráficos, tablas, notas, etcétera) no debe ser inferior a 15 páginas ni superior a 20. La fuente será Times New Roman, tamaño 12 y espaciado doble. Estar paginado en la parte inferior derecha de cada página.

3. En la primera página se hará constar el título del artículo que deberá ser breve, claro, preciso e informativo y la fecha de conclusión del mismo. Nombre y dos apellidos del autor o autores, filiación institucional, dirección, teléfono y correo electrónico de cada uno de ellos, así como la forma en que desean que sus datos aparezcan.

4. En la segunda página del texto se incluirá:

- El título.

- Un resumen del trabajo con una extensión máxima de 10 líneas con la siguiente estructura: objetivo, método y principal resultado o conclusión.

- De 2 a 6 palabras clave que no sean coincidentes con el título.

- De 1 a 5 códigos de materias del Journal of Economic Literature (clasificación JEL) para lo cual pueden acceder a la siguiente dirección electrónica:

https://www.aeaweb.org/jel/guide/jel.php

5. En las siguientes páginas se incluirán el texto, la información gráfica y la bibliografía con la siguiente organización.

- Se incluirá, por este orden, introducción, desarrollo, conclusiones y bibliografía y anexos si los hubiera. Los apartados y subapartados se numerarán en arábigos respondiendo a una sucesión continuada utilizando un punto para separar los niveles de división, según el siguiente modelo:

\section{Título del apartado}

\subsection{Título del apartado}

\subsubsection{Título del apartado}

\section{Título del apartado}

- Las notas de pie de página irán integradas en el texto y su contenido debe estar al final de su misma página en tamaño 10 y espacio sencillo.

- En un archivo Excel independiente se incluirá la representación gráfica (cuadros, gráficos, diagramas, figuras, etc.), que debe llevar título, estar numerada y referenciada en el texto.

En la parte inferior se incluirá la fuente de información y/o notas aclaratorias.

- Las citas de libros y artículos en el texto, se indicarán entre paréntesis con el apellido del autor y el año. Ej.: (Martínez, 1991).

- Las referencias a siglas deben ir acompañadas, en la primera ocasión en que se citen, de su significado completo.

- La bibliografía se ordenará alfabéticamente siguiendo las normas de la American Psychological Association (Harvard-APA): http://cibem.org/paginas/img/apa6.pdf

Libros

APELLIDOS, A.A. (año de publicación). Título del libro (edición) (volumen). Ciudad: Editorial.

Artículo en revista científica

APELLIDOS, A.A. (año de publicación). «Título del artículo». Título de la revista, volumen (número), números de páginas.

\section{Documento en línea}

APELLIDOS, A.A. u ORGANISMO (año, mes de publicación). Título, [en línea]. Ciudad: Editorial. Disponible en:

http://cenamb.rect.ucv.ve/siamaz/dicciona/canaima/canaima2.htm [Recuperado: 2000, 3 de junio]. 